\title{
Analisa Perilaku Arah Kendaraan dengan Variasi Posisi Titik Berat, Sudut Belok dan Kecepatan Pada Mobil Formula Sapuangin Speed 3
}

\author{
Tjahyadi Rizky Pradana dan I Nyoman Sutantra \\ Teknik Mesin, Fakultas Teknik Industri, Institut Teknologi Sepuluh Nopember (ITS) \\ Jl. Arief Rahman Hakim, Surabaya 60111 Indonesia \\ e-mail: tantra@me.its.ac.id
}

\begin{abstract}
Abstrak - Pada tahun 2015, ITS Team Sapuangin untuk ketiga kalinya mengikuti lomba Student Formula Japan yang diadakan oleh Japan Society of Automotive Enginee (JSAE). Target Team Sapuangin yaitu menjuarai skid-pad. Namun kenyataannya ITS Team Sapuangin hanya mampu menyelesaikan skid-pad dengan waktu 5,73 detik. Pada perlombaan ini, TU Graz adalah tim yang berhasil menjuarai perlombaan skid-pad ini dengan waktu 5,03 detik. Kendala yang dialami Sapuangin Speed 3 adalah sulit dikendalikan dan mengalami understeer maupun oversteer. Permasalahan ini akan dicoba dianalisa penyebabnya agar pada tahun berikutnya mobil Sapuangin Speed 4 bisa tampil dengan baik. Dalam tugas akhir ini, dilakukan analisa tentang perilaku arah kendaraan pada mobil formula Sapuangin Speed 3 dengan variasi posisi titik berat dan kecepatan di lintasan skid pad. Pada awalnya, menentukan posisi titik berat untuk dianalisa, kemudian menghitung gaya-gaya yang terjadi pada ban yang mampu mempengaruhi perilaku arah pada kendaraan, lalu divariasikan dengan kecepatan tertentu hingga mampu memperoleh waktu yang optimal. Sedangkan pada steering system yaitu meneliti sudut belok agar mencapai kondisi ideal (Ackermann). Dari penelitian yang telah dilakukan, diperoleh posisi titik berat yang optimal yaitu tepat ditengah (50\% : $50 \%$ ) dengan Kus 0,0678 pada radius $8,982 \mathrm{~m}$. Kemudian dari analisa skid kendaraan mengalami oversteer pada yaw rate sebesar 2,2677. Dari analisa steering Pengaturan steering pada Sapuangin Speed 3, settingan yang cocok yaitu menggunakan settingan bawah. Karena mobil Sapuangin Speed 3 cenderung mengalami understeer, namun mobil Sapuangin Speed 3 mengalami oversteer akibat yaw rate settingan atas merupakan settingan terbaik karena untuk mengatasi oversteer yang berlebih.
\end{abstract}

Kata Kunci-analisa guling, analisa skid, analisa slip, kecepatan maksimum, oversteer, sapuangin speed 3, skid pad understeer, waktu terbaik.

\section{PENDAHULUAN}

$\mathrm{P}$ ADA tahun 2015, ITS Team Sapuangin untuk ketiga kalinya mengikuti lomba Student Formula Japan yang diadakan oleh Japan Society of Automotive Enginee (JSAE). Dalam lomba ini setiap tim diharuskan untuk mengikuti dynamic event dalam perlombaan tersebut, antara lain acceleration, skid-pad, autocross dan endurance. Target Team Sapuangin yaitu menjuarai skid-pad, karena mobil Sapuangin Speed 4 memiliki mesin dengan kapasitas yang kecil dibandingkan dengan tim-tim dari negara lain. Namun kenyataannya ITS Team Sapuangin hanya mampu menyelesaikan skid-pad dengan waktu 5,73 detik. Pada perlombaan ini, TU Graz adalah tim yang berhasil menjuarai perlombaan skid-pad ini dengan waktu 5,03 detik.

Kendala yang dialami Sapuangin Speed 3 adalah sulit dikendalikan dan mengalami understeer maupun oversteer. Dengan kondisi kendaraan yang sulit diprediksi seperti ini, pengemudi harus selalu melakukan koreksi, sehingga sulit untuk mendapatkan waktu capaian yang baik. Permasalahan ini akan dicoba dianalisa penyebabnya agar pada tahun berikutnya mobil Sapuangin Speed 4 bisa tampil dengan baik.

Perilaku tidak stabilnya suatu kendaraan terdapat banyak faktor yang menyebabkan kendaraan mengalami oversteer maupun understeer, salah satu penyebabnya adalah posisi titik berat. Dalam merancang mobil balap, berdasarkan buku "Motor Car Development/Fabrication Guide"[1], posisi titik berat berpengaruh terhadap stabilitas kendaraan. Letak posisi titik berat bila berada di depan, maka kendaraan akan mengalami understeer. Sebaliknya, apabila posisi titik berat kendaraan berada di belakang, kendaraan akan mengalami oversteer. Pada saat kendaraan belok dengan kecepatan yang sangat rendah dan sudut belok yang tetap (steady-state cornering), sudut slip yang terjadi hanya pada roda depan. Ketika kendaraan berbelok dengan kecepatan tinggi, sudut slip mulai terjadi pada roda depan dan roda belakang. Maka dari itu kendaraan akan mengalami oversteer maupun understeer.

Namun merancang mobil balap berbeda dengan mobil sehari-hari. Pada mobil balap, power to weight ratio lebih besar dari mobil biasa. Hal ini membuat roda penggerak menjadi mudah mengalami slip saat berakselerasi. Karena itu dalam merancang mobil balap analisa understeer dan oversteer harus mempertimbangkan sudut slip pada roda belakang yang merupakan penggerak.

Pada mobil Sapuangin Speed 3, letak posisi titik berat berada di depan dengan maksud meningkatkan traksi pada roda depan dan mengurangi traksi di roda belakang sehingga pengemudi bisa memanfaatkan akselerasi untuk memutar bagian belakang mobil. Namun hal ini ternyata sulit dilakukan 
karena kendaraan masih mengalami undesteer pada saat berakselerasi karena adanya Limited Slip Differential di roda belakang.

Dalam tugas akhir ini, dilakukan analisa tentang stabilitas arah gerak belok kendaraan pada mobil formula Sapuangin Speed 3 ini pada lintasan skid-pad dengan mengabaikan pengaruh Limited Slip Differential dan menganggap chassis mobil cukup rigid untuk melakukan skid-pad dengan baik. Hasil analisa diharapkan dapat memberikan arahan pada desain mobil formula Sapuangin Speed 4 untuk mendapatkan kemampuan maneuver yang lebih baik supaya dapat memperoleh hasil yang maksimal pada kompetisi Student Formula japan 2016.

\section{URAIAN PENELITIAN}

Pada penyusunan tugas akhir ini prosedur penelitian dilakukan dalam empat tahap. Tahap awal, melakukan analisaanalisa dengan sumber studi literatur terhadap buku, jurnal dan penelitian terdahulu tentang kestabilan arah kendaraan. Selanjutnya adalah penentuan objek mobil yang akan diteliti yaitu mobil formula Sapuangin Speed 3 dengan spesifikasi massa total dengan pengemudi $287,5 \mathrm{~kg}$, wheelbase sebesar $1555 \mathrm{~mm}$, trackwidth depan sebesar $1257 \mathrm{~mm}$, trackwidth belakang sebesar $1198 \mathrm{~mm}$ dan tinggi center of gravity sebesar $300 \mathrm{~mm}$. Spesifikasi kendaraan yang akan diuji dapat dilihat pada tabel di bawah ini.

\begin{tabular}{|c|c|}
\hline \multicolumn{2}{|c|}{ Dimensi } \\
\hline Track width depan & $1257 \mathrm{~mm}$ \\
\hline Track width belakang & $1198 \mathrm{~mm}$ \\
\hline Panjang kendaraan & $2804 \mathrm{~mm}$ \\
\hline Lebar kendaraan & $1442 \mathrm{~mm}$ \\
\hline Tinggi kendaraan & $1295 \mathrm{~mm}$ \\
\hline Jarak sumbu roda & $1555 \mathrm{~mm}$ \\
\hline \multicolumn{2}{|c|}{ Berat } \\
\hline Massa total berpenumpang & $287.5 \mathrm{~kg}$ \\
\hline Berat total berpenumpang & $2820.38 \mathrm{~N}$ \\
\hline Koefisien suspensi & $25410 \mathrm{~N} / \mathrm{m}$ \\
\hline \multicolumn{2}{|c|}{ Titik berat } \\
\hline \multicolumn{2}{|c|}{ Titik Berat Awal (47.4\% : 52.6\%) } \\
\hline Tinggi CG & $0.3 \mathrm{~m}$ \\
\hline Wf & $1471.5 \mathrm{~N}$ \\
\hline $\mathrm{Wr}$ & $1339.065 \mathrm{~N}$ \\
\hline \multicolumn{2}{|l|}{ Posisi $50 \%: 50 \%$} \\
\hline Wf & $1410.187 \mathrm{~N}$ \\
\hline $\mathrm{Wr}$ & $1410.187 \mathrm{~N}$ \\
\hline \multicolumn{2}{|l|}{ Posisi 45\% : 55\% } \\
\hline Wf & $1551.2 \mathrm{~N}$ \\
\hline $\mathrm{Wr}$ & $1269.168 \mathrm{~N}$ \\
\hline \multicolumn{2}{|l|}{ Posisi 55\% : 45\% } \\
\hline Wf & $1269.168 \mathrm{~N}$ \\
\hline $\mathrm{Wr}$ & $1551.2 \mathrm{~N}$ \\
\hline \multicolumn{2}{|c|}{ Aerodinamika } \\
\hline Luas frontal area & $0.78 \mathrm{~mm}^{2}$ \\
\hline Massa jenis angin & $1.25 \mathrm{~kg} / \mathrm{m}^{3}$ \\
\hline Koefisien drag & 0.58 \\
\hline \multicolumn{2}{|c|}{ Ban ( Hoosier 20.5x7 R13) } \\
\hline Jenis ban & Radial gundul \\
\hline Diameter roda & 20.5 inch \\
\hline Lebar roda & 7 inch \\
\hline Koefisien adhesi jalan & 0.9 \\
\hline
\end{tabular}

Kemudian mobil Sapuangin Speed 3 dilakukan analisa kestabilan arah pada variasi posisi titik berat 50:50 (tepat di tengah), 45:55 (bergeser ke kiri), 55:45 (bergeser ke kanan). Tahap selanjutnya kestabilan arah dilakukan analisa berdasarkan variasi kecepatan dan sudut belok untuk mengetahui kendaraan mengalami skid atau guling. Dari analisa tersebut, kemudian dilakukan analisa pada lintasan skid-pad pada tes dinamik Student Formula Japan sehingga dapat mengetahui kecepatan, sudut belok dan waktu tempuh terbaik.

Penentuan rancangan titik berat kendaraan dilakukan berdasarkan gaya reaksi yang terjadi pada ban saat diam kendaraan statis sehingga diperoleh rancangan posisi titik berat sebagai berikut.

Tabel 2 Rancangan variasi posisi titik berat mobil formula Sapuangin Speed 3.

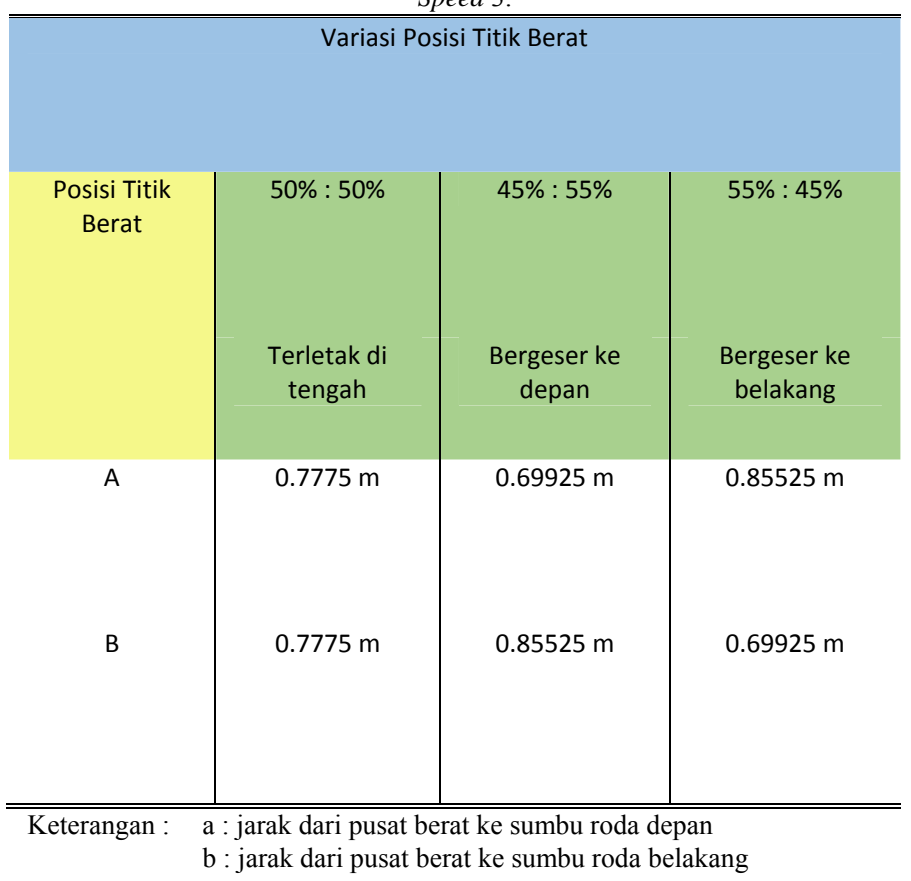

Adapun rancangan posisi titik berat dapat ditunjukkan pada gambar di bawah ini.

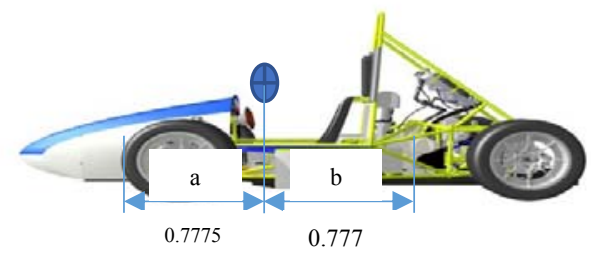

Gambar 1. Rancangan titik berat mobil Sapuangin Speed 3 dengan variasi titik berat 50:50

Setelah menentukan posisi titik berat yang optimal, selanjutnya mengetahui perilaku belok Ackermann $\left(\mathrm{R}_{\mathrm{ack}}\right)$ dan sudut side slip ( $\beta$ ) ssperti gambar berikut. 


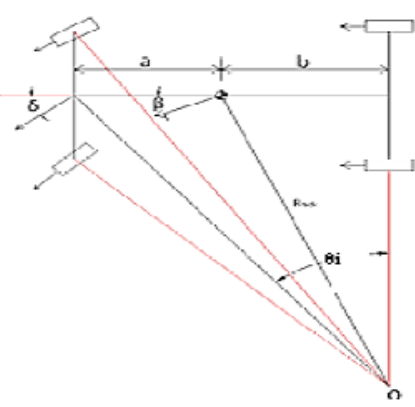

Gambar 2. Kinematika kendaraan belok Ackermann[2]

Sehingga diperoleh persamaan sebagai berikut.

$\mathrm{R}_{\mathrm{ack}}=\frac{a+b}{\delta_{f}} 57,29$

$\beta=\arcsin \left(\frac{b}{R_{a c k}}\right)$

Selanjutnya menghitung gaya-gaya dan momen yang ada pada kendaraan saat berbelok.

$$
\begin{aligned}
& F_{c f}=\frac{\partial}{a+b} \operatorname{Becos} \beta \\
& F_{c f}=\frac{\partial}{a+b} \operatorname{Fegag} \beta \\
& M_{\mathrm{r}}=F_{\theta} \cos \beta{ }_{n} r_{\theta}+W{ }_{n} r_{\theta}, \gamma \\
& M_{p}=\left(R \sin \beta-E_{\alpha} r_{0}+W_{\mathrm{n}} r_{\theta}+\psi\right. \\
& F_{d}=\frac{1}{2}, C_{d}, \rho \cdot V_{g}^{Q}, A_{f}
\end{aligned}
$$

Setekah diperoleh besar gaya-gaya dan momen yang bekerja saat belok, kemudian dilakukan analisa gaya-gaya pada ban seperti yang ditunjukkan gambar sebagai berikut.

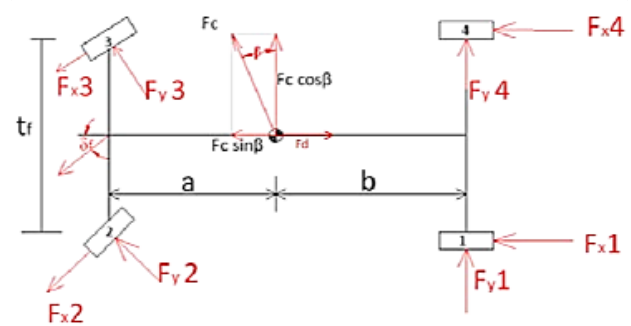

Gambar 3. Gaya pada arah-x dan arah-y[2]

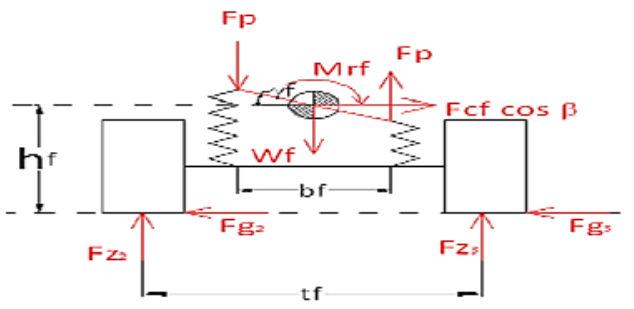

Gambar 4. Pengaruh gaya centrifugal pada momen rolling[3]

$E_{x_{2}}=E_{x_{4}}=\frac{n}{2(\alpha+b)}\left(E_{0} \sin \beta-F_{d}^{\prime}\right)-K_{m}$

$$
\begin{aligned}
& F_{V_{4}}=F_{V_{4}}=\frac{a}{2(\alpha+b)} F_{\varepsilon} \cos \beta
\end{aligned}
$$

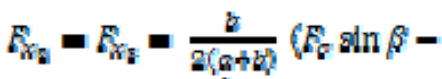

$$
\begin{aligned}
& \text { F. } \cos _{f}=\frac{\partial}{2(a+b)} R_{f} \cos \beta \sin \theta_{f}=R_{r f} \\
& E_{h}=E_{W}=\frac{b}{2(a+b)} E_{\theta} \cos \beta \cos \delta_{f}+\frac{b}{2(a+b)}\left(E_{\theta} \sin \beta-\right. \\
& \left.F_{6}\right) \sin \theta_{f}
\end{aligned}
$$

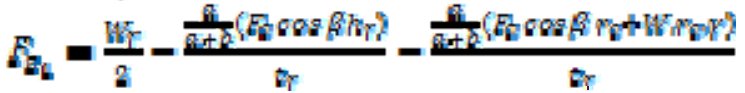

$$
\begin{aligned}
& F_{z_{4}}=\frac{W_{r}}{2}+\frac{\frac{a}{a+b}\left(B_{0} \cos \beta h_{r}\right)}{t_{r}}+\frac{\frac{a}{a+b}\left(B_{0} \cos \beta r_{0}+W r_{0} \psi \gamma\right)}{t_{r}} \\
& E_{\mathrm{D}_{\mathrm{a}}}=\frac{W_{f}}{2}-\frac{\frac{b}{a+b}\left(E_{e} \cos \beta h_{f}\right)}{t_{f}}-\frac{\frac{b}{a+b}\left(E_{e} \cos \beta r_{e}+W \cdot r_{c} \cdot r\right)}{t_{f}}
\end{aligned}
$$

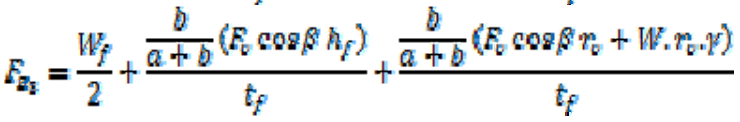

Setelah melakukan analisa gaya-gaya pada ban, kemudian dilakukan analisa saat kendaraan mengalami skid seperti gambar sebagai berikut.

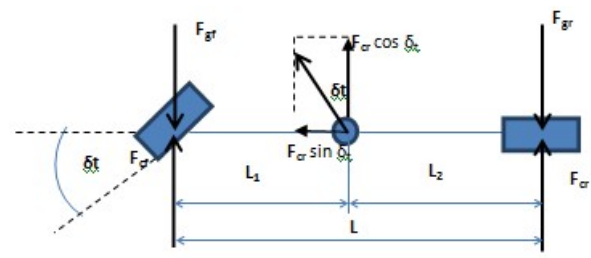

Gambar 5. Analisa skid dengan menggunakan model sepeda[3]

$$
\begin{aligned}
& E_{g f}=H_{1} E_{a f} \\
& E_{g n}=\mu E_{a r}
\end{aligned}
$$

Kemudian menghitung sudut slip yang terjadi pada ban. Mobil Sapuangin Speed 3 menggunakan ban radial gundul. Dapat dihitung dengan menggunakan persamaan sebagai berikut [4].

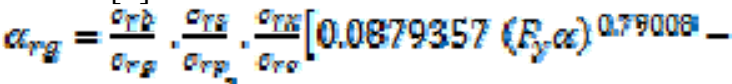

$$
\begin{aligned}
& \left.0.005277\left(E_{z}\right)\right]
\end{aligned}
$$

Dimana:

$\alpha_{\mathrm{rg}} \quad=$ sudut slip ban radial gundul

$\mathrm{C}_{\mathrm{rb}}=0.00301003\left(\mathrm{~F}_{\mathrm{y}} \alpha\right)^{1.207861}$

$\mathrm{C}_{\mathrm{rg}}=0.0023636\left(\mathrm{~F}_{\mathrm{y}} \alpha\right)^{1.222203}$

$\mathrm{C}_{\mathrm{rp}}=33.5+5.30(\mathrm{P})-0.0916(\mathrm{P})^{2}$

$\mathrm{C}_{\mathrm{rs}}=33.5+5.30\left(\mathrm{P}_{\mathrm{s}}\right)-0.0916\left(\mathrm{P}_{\mathrm{s}}\right)^{2}$

$\mathrm{P} \quad=$ tekanan ban (psi)

$\mathrm{P}_{\mathrm{s}} \quad=$ tekanan ban standar $25 \mathrm{psi}$

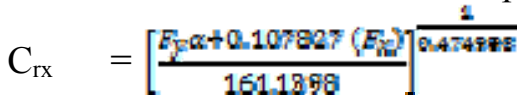




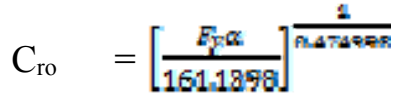

Untuk menghitung perilaku belok kendaraan, dapat diketahui dengan menghitung nilai understeer index (Kus) sebagai berikut[4].

$K_{\alpha g}=\left(\alpha_{f}-\alpha_{r}\right) \frac{a R}{V^{2}}$

Apabila nilai Kus positif menunjukkan kendaraan mengalami understeer, sebaliknya, jika Kus negative kendaraan mengalami oversteer.

Saat kendaraan berbelok, maka kendaraan mengalami gerakan berputar atau yaw[4]. Dengan dasar konsep kinematika dapat dihitung dengan persamaan sebagai berikut.

$$
Y_{m}=\frac{V}{R_{m}}
$$

Sistem kemudi pada kendaraan memiliki peranan yang penting dalam berbelok. Sistem kemudi yang ideal dapat ditunjukkan seperti gambar sebagai berikut[5].

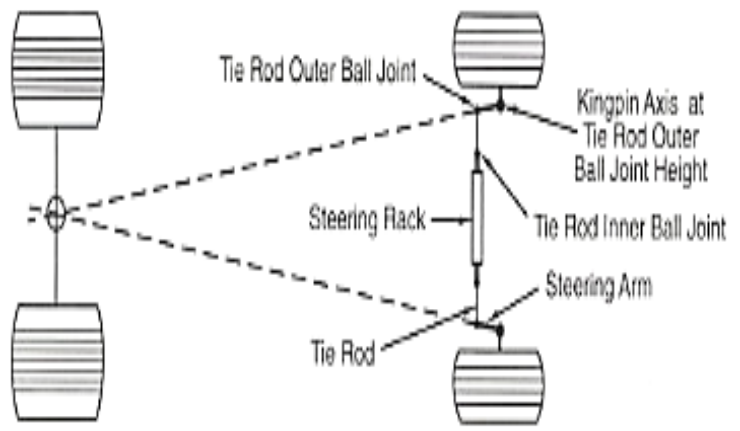

Gambar 6. Ackermann steering geometry[5]

\section{HASIL DISKUSI}

\section{A. Analisa Posisi Titik Berat}

Berdasarkan hasil analisa, diperoleh posisi titik berat yang optimal yaitu posisi titik berat 50:50 (berada di tengah) seperti yang ditunjukkan pada grafik di bawah ini.

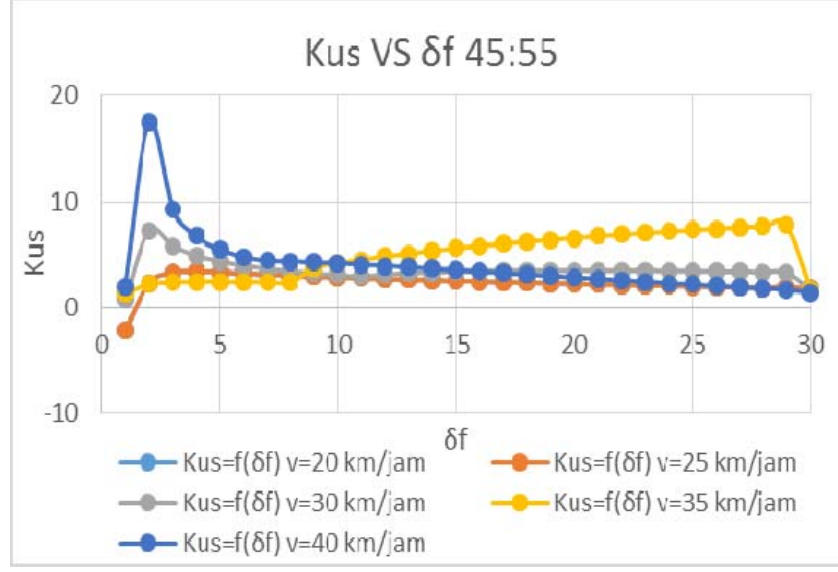

Gambar 7. Grafik Kus VS sudut belok pada posisi titik berat 45:55

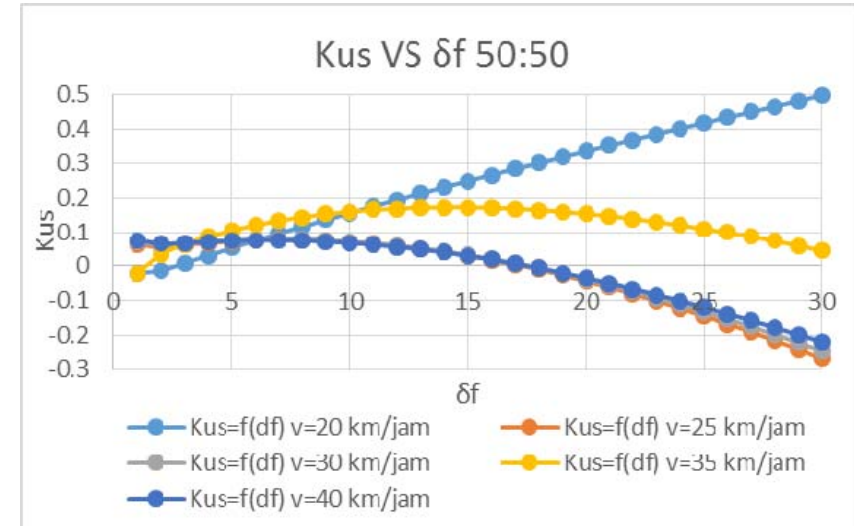

Gambar 8. Grafik Kus VS sudut belok pada posisi titik berat 50:50

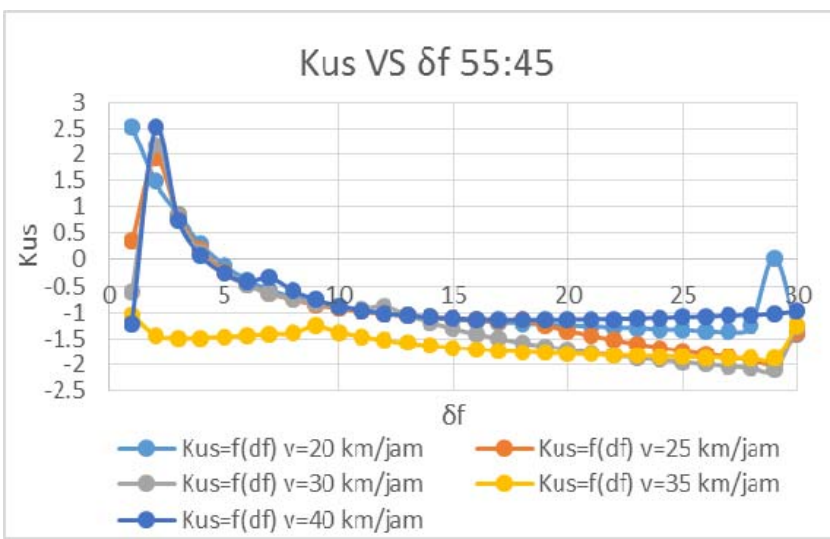

Gambar 9. Grafik Kus VS sudut belok pada posisi titik berat 55:45

Dari grafik tersebut menunjukkan posisi titik berat ini mempunyai nilai Kus yang rendah jika dibandingkan dengan variasi titik berat yang lain dan cenderung understeer. Oleh sebab itu, posisi titik berat adalahn yang optimum.

\section{B. Analisa Pada Lintasan Skid-Pad}

Dengan melakukan analisa secara perhitungan, dapat diperoleh waktu tempuh pada lintasan skid-pad.

Tabel 3. Kecepatan, sudut belok dan waktu tempuh pada lintasan skid-pad

\begin{tabular}{|c|c|c|c|c|c|}
\hline $\begin{array}{c}\mathrm{V} \\
(\mathrm{m} / \mathrm{s})\end{array}$ & $\begin{array}{l}\delta f \\
\text { (o) }\end{array}$ & $\begin{array}{l}\mathrm{Rn} \\
(\mathrm{m})\end{array}$ & Kus & $\begin{array}{c}\text { Keliling } \\
\text { (m) }\end{array}$ & $\begin{array}{c}\text { Waktu } \\
\text { (s) }\end{array}$ \\
\hline \multirow[t]{3}{*}{5.55} & 9 & 9.939955 & 0.136996 & 62.42291 & 44.97179 \\
\hline & 10 & 8.952161 & 0.156713 & 56.21957 & 40.50267 \\
\hline & 11 & 8.143841 & 0.175991 & 51.14332 & 36.84555 \\
\hline \multirow[t]{3}{*}{6.94} & 9 & 9.933151 & 0.075214 & 62.38019 & 33.79748 \\
\hline & 10 & 8.93804 & 0.07156 & 56.13089 & 31.21795 \\
\hline & 11 & 8.12314 & 0.066298 & 51.01332 & 29.0066 \\
\hline \multirow[t]{3}{*}{8.33} & 9 & 9.957941 & 0.075656 & 62.53587 & 27.08981 \\
\hline & 10 & 8.959474 & 0.07188 & 56.2655 & 25.41238 \\
\hline & 11 & 8.141597 & 0.066628 & 51.12923 & 23.93209 \\
\hline \multirow[t]{3}{*}{9.72} & 9 & 10.01127 & 0.111343 & 62.87077 & 22.6161 \\
\hline & 10 & 9.01136 & 0.112607 & 56.59134 & 21.43848 \\
\hline & 11 & 8.191936 & 0.112368 & 51.44536 & 20.37849 \\
\hline
\end{tabular}




$$
11.11
$$

\begin{tabular}{ccccc}
9 & 9.992378 & 0.071747 & 62.75214 & 19.41934 \\
\hline 10 & 8.988152 & 0.067782 & 56.44559 & 18.54729 \\
\hline 11 & 8.165039 & 0.06253 & 51.27644 & 17.75098 \\
\hline
\end{tabular}

\section{Analisa Skid Pada Lintasan Skid-Pad}

Berdasarkan hasil perhitungan analisa skid di atas, kendaraan mengalami oversteer karena dipengaruhi oleh skid. Pengaruh antara analisa sebelum analisa skid dan sesudah dikenai akibat skid dapat ditunjukkan dengan gambar sebagai berikut.

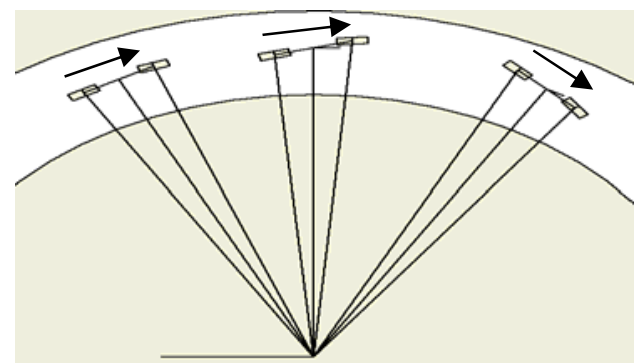

Gambar 8. Ilustrasi pengaruh yaw rate pada kendaraan oversteer

Pada saat kendaraan belum dikenai skid, kendaraan mengalami kondisi understeer yang masih lebih mudah untuk dikendalikan. Setelah dikenai skid kendaraan mengalami oversteer. Kendaraan dengan tipikal understeer cenderung susah untuk belok dan memerlukan sudut belok yang lebih besar untuk melakukan belok. Maka dari itu driver harus sangat ahli dalam mengendalikan kendaraan karena driver harus melakukan koreksi terhadap steering dan juga kendaraan harus dibuat menjadi sedikit oversteer agar kendaraan bisa mendekati kondisi netral.

Mobil Sapuangin Speed 3 memiliki 3 settingan pada pengaturan sistem kemudi. Dari hasil pengukuran diperoleh data dan grafik sebagai berikut.

Tabel 4. Data hasil pengukuran settingan pada mobil Sapuangin Speed 3

\begin{tabular}{|c|c|c|c|c|c|c|c|}
\hline \multicolumn{2}{|c|}{ Settingan bawah } & \multicolumn{2}{c|}{ Settingan tengah } & \multicolumn{2}{c|}{ Settingan atas } & \multicolumn{2}{c|}{ Ackermann } \\
\hline df kanan & df kiri & df kanan & df kiri & df kanan & df kiri & df kanan & df kiri \\
\hline 5 & 6.18 & 5 & 6.15 & 5 & 5.25 & 4.82 & 5.17 \\
\hline 10 & 12.36 & 10 & 12.3 & 10 & 10.5 & 9.3 & 10.68 \\
\hline 15 & 18.54 & 15 & 18.45 & 15 & 15.75 & 13.43 & 16.49 \\
\hline 20 & 24.72 & 20 & 24.6 & 20 & 21 & 17.25 & 22.52 \\
\hline
\end{tabular}

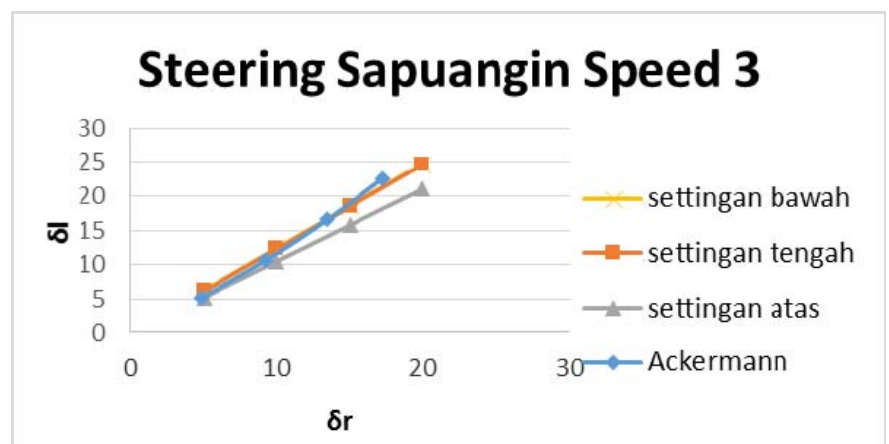

Gambar 9. Grafik perbandingan pengaturan steering Sapuangin Speed 3

\section{KESIMPULAN}

Dari hasil perhitungan waktu pada lintasan skid-pad, kendaraan formula Sapuangin Speed 3 memperoleh waktu terbaik secara perhitungan dengan waktu 5,0832 s dan sudut belok $10^{\circ}$. Kendaraan mengalami understeer diakibatkan adanya sudut slip yang terbentuk pada roda depan lebih besar dibandingkan pada roda belakang. Dengan adanya penambahan beban akan mempengaruhi perpindahan dari letak posisi titik berat. Semakin bergeser beban ke depan maka kendaraan cenderung mengalami understeer. Semakin bergeser beban ke belakang maka kendaraan cenderung mengalami oversteer.

\section{DAFTAR PUSTAKA}

[1] Shimada, Yukio. 2007. Motor Car Development/Fabrican Guide For Student and Junior Engineers. Society of Automotive Engineers of Japan, Inc. Tokyo.

[2] Kaunang, Deni Rizal. 2013. Analisa Stabilitas Arah Pada Kendaraan Formula Sapu Angin Speed Berdasarkan Variasi Posisi Titik Berat, Kecepatan dan Tes Dinamik Student Formula Japan 2013.

[3] Fitrawan, M.Ashadi. Analisa Steering Linkage pada INKA GEA dan Stabilitas Dengan Variabel Kecepatan, Sudut Belok Terhadap Beban Muatan dan Posisi Muatan. 2012.

[4] Sutantra, I Nyoman dan Sampurno, Bambang. 2010. Teknologi Otomotif. Edisi kedua. Guna Widya: Surabaya.

[5] Milliken, William F. dan Milliken, Douglas L. 1911. Race Car Vehicle Dynamics. Society of Automotive Engineers, Inc. Warrandale. 